\title{
Prediction of industrial tomato hybrids from agronomic traits and ISSR molecular markers
}

\author{
A.S.T. Figueiredo ${ }^{1}$, J.T.V. Resende ${ }^{2}$, M.V. Faria ${ }^{2}$, P.R. Da-Silva ${ }^{3}$, \\ B.S. Fagundes ${ }^{4}$ and R.G.F. Morales ${ }^{5}$ \\ ${ }^{1}$ Departamento de Pesquisa em Melhoramento de Hortaliças, \\ Estação de Pesquisa e Desenvolvimento Sakata, Bragança Paulista, SP, Brasil \\ ${ }^{2}$ Departamento de Agronomia, Campus Universitário Cedeteg, \\ Universidade Estadual do Centro-Oeste, Guarapuava, PR, Brasil \\ ${ }^{3}$ Departamento de Biologia, Campus Universitário Cedeteg, \\ Universidade Estadual do Centro-Oeste, Guarapuava, PR, Brasil \\ ${ }^{4}$ Departamento de Ciências Biológicas, Universidade Estadual do Centro-Oeste, \\ Guarapuava, PR, Brasil \\ ${ }^{5}$ Empresa de Pesquisa Agropecuária e Extensão Rural de Santa Catarina, \\ Estação Experimental de Itajaí, Itajaí, SC, Brasil \\ Corresponding author: A.S.T. Figueiredo \\ E-mail: alex.figueiredo@sakata.com.br / alexstfigueiredo@gmail.com
}

Genet. Mol. Res. 15 (2): gmr.15027981

Received November 4, 2015

Accepted December 21, 2015

Published May 13, 2016

DOI http://dx.doi.org/10.4238/gmr.15027981

\begin{abstract}
Heterosis is a highly relevant phenomenon in plant breeding. This condition is usually established in hybrids derived from crosses of highly divergent parents. The success of a breeder in obtaining heterosis is directly related to the correct identification of genetically contrasting parents. Currently, the diallel cross is the most commonly used methodology to detect contrasting parents; however, it is a time- and cost-consuming procedure. Therefore, new tools capable of performing this task quickly and accurately are required. Thus, the purpose of this study was to estimate the genetic divergence
\end{abstract}


in industrial tomato lines, based on agronomic traits, and to compare with estimates obtained using inter-simple sequence repeat (ISSR) molecular markers. The genetic divergence among 10 industrial tomato lines, based on nine morphological characters and 12 ISSR primers was analyzed. For data analysis, Pearson and Spearman correlation coefficients were calculated between the genetic dissimilarity measures estimated by Mahalanobis distance and Jaccard's coefficient of genetic dissimilarity from the heterosis estimates, combining ability, and means of important traits of industrial tomato. The ISSR markers efficiently detected contrasting parents for hybrid production in tomato. Parent RVTD-08 was indicated as the most divergent, both by molecular and morphological markers, that positively contributed to increased heterosis and by the specific combining ability in the crosses in which it participated. The genetic dissimilarity estimated by ISSR molecular markers aided the identification of the best hybrids of the experiment in terms of total fruit yield, pulp yield, and soluble solids content.

Key words: Solanum lycopersicum; Pre-breeding; Heterosis; Genetic diversity

\section{INTRODUCTION}

Tomato (Solanum lycopersicum L.) is an autogamous plant from which hybrids can be derived, ensuring a series of quantitative and qualitative benefits for producers and consumers (Santos et al., 2011). Currently, hybrid cultivars are planted on virtually the entire acreage of industrial tomato in Brazil (Vilela et al., 2012). This stimulates public and private breeding programs to seek hybrids with good performance and fruit quality, to meet the growers' demand (Melo et al., 2009).

Divergent parents are expected to share few alleles and to have high allelic complementarity when combined, restoring the hybrid vigor, which is expressed in heterosis (Cruz et al., 2011). Predictive techniques based on multivariate statistical procedures can estimate the genetic distance between parents, assisting the breeder in the definition of crosses between the most divergent parents by increasing the chances of developing a high-yielding hybrid in less time (Oliveira et al., 1998; Moreira et al., 2005; Gonçalves et al., 2008, Rocha et al., 2010; Reddy et al., 2013, Mattedi et al., 2014).

Quantitative agronomic traits are phenotypic markers widely used in genetic divergence studies (Morales et al., 2011a) with the advantage of being directly linked to the coding regions of the genome aside from the low acquisition cost (Gonçalves et al., 2008). However, environmental influences and the need to evaluate some variables in the adult plant stage are the main disadvantages of this marker group, hampering their use. On the other hand, the polymorphism observed at the molecular level can provide estimates of genetic divergence based on a direct analysis of DNA. Among the series of DNA molecular markers, the intersimple sequence repeat (ISSR) markers are particularly noteworthy, and are based on the SSR polymorphisms (Morales et al., 2011a). These markers use primers from 16 to 25 bp with "di" or "tri" nucleotide sequences, at high annealing temperature that can amplify bands of 100 to 3000 bp by polymerase chain reaction (PCR), with high reproducibility; thus, these markers are reliable in genetic divergence studies (Aguilera et al., 2011). 
Few previous studies have tested the use of estimates of genetic divergence among tomato parents as an orientation for crosses (Maluf et al., 1983; Mulge et al., 2012). Thus, the purpose of this study was to estimate the genetic divergence among industrial tomato lines, based on agronomic and ISSR molecular markers, to establish estimates of heterosis, means, and combining ability of the hybrids derived from diallel crosses.

\section{MATERIAL AND METHODS}

\section{Lines and crosses}

Ten lines of industrial tomato (RVTD-01, RVTD-02, RVTD-03, RVTD-04, RVTD-05, RVTD-06, RVTD-07, RVTD-08, RVTD-09, and RVTD-10) and 45 single-cross experimental hybrids derived from crosses among them, were evaluated in the field, in a complete block design with randomized treatments and three replications, in the horticulture sector of the Research Center for Vegetables of Universidade Estadual do Centro-Oeste, Guarapuava, PR, Brazil. A detailed description with the main traits of the lines used in the experiment is given in Table 1. Each experimental unit consisted of two planting rows, spaced $1.20 \mathrm{~m}$ apart, with nine plants per row, spaced $0.35 \mathrm{~m}$ apart. The two tomato plants at either end were excluded from the analysis, so that the evaluated experimental area was $5.46 \mathrm{~m}^{2}$.

Table 1. Description of ten inbred lines of tomatoes used in the experiment. Average values of total yield of fruits (PY), average mass of fruit (MM), cycle (CL), content soluble solids (SS), diameter of the stalk scar (DSS), length of fruit (LF), diameter of fruit (DF), relation between length and width of fruit (LF/DF), format of fruit (FrF), and coloring of fruit (CLF) of ten inbreed lines of tomatoes for industrial processing.

\begin{tabular}{l|c|c|c|c|c|c|c|c|c|c}
\hline Genitor & $\begin{array}{c}\text { PY } \\
(\mathrm{t} / \mathrm{ha})\end{array}$ & $\begin{array}{c}\text { MM } \\
(\mathrm{g} / \text { fruit) }\end{array}$ & $\begin{array}{c}\text { CL } \\
(\text { days })\end{array}$ & $\begin{array}{c}\text { SS } \\
\left({ }^{\circ} \text { Brix }\right)\end{array}$ & $\begin{array}{c}\text { DS } \\
(\mathrm{mm})\end{array}$ & $\begin{array}{c}\text { CF } \\
(\mathrm{mm})\end{array}$ & $\begin{array}{c}\text { DF } \\
(\mathrm{mm})\end{array}$ & CF/LF & FrF & CLF \\
\hline RVTD-01 & 35.17 & 80.78 & 122 & 4.06 & 8.47 & 53.67 & 51.67 & 1.04 & SC & Am \\
\hline RVTD-02 & 40.13 & 56.34 & 120 & 4.23 & 7.29 & 58.81 & 51.47 & 1.14 & SC & VC \\
\hline RVTD-03 & 55.82 & 74.23 & 124 & 4.10 & 8.53 & 65.15 & 55.27 & 1.18 & IT & VC \\
\hline RVTD-04 & 38.53 & 67.96 & 120 & 4.10 & 9.99 & 61.95 & 53.35 & 1.17 & IT & VI \\
\hline RVTD-05 & 48.43 & 56.71 & 121 & 4.16 & 7.34 & 62.27 & 52.28 & 1.16 & IT & VC \\
\hline RVTD-06 & 43.15 & 74.22 & 121 & 4.03 & 8.83 & 60.14 & 52.54 & 1.15 & SC & VI \\
\hline RVTD-07 & 60.80 & 57.35 & 115 & 3.83 & 8.97 & 61.22 & 51.90 & 1.18 & IT & VC \\
\hline RVTD-08 & 50.75 & 57.54 & 121 & 4.66 & 7.97 & 59.40 & 52.62 & 1.13 & IT & VI \\
\hline RVTD-09 & 40.35 & 46.46 & 123 & 4.26 & 6.61 & 46.95 & 48.39 & 0.97 & SL & VI \\
\hline RVTD-10 & 43.90 & 63.14 & 121 & 4.70 & 8.22 & 62.57 & 52.15 & 1.21 & IT & VI \\
\hline
\end{tabular}

$\mathrm{SC}=$ Santa Cruz fruit; $\mathrm{IT}=$ Italiano fruit; $\mathrm{SL}=$ Saladete fruit; $\mathrm{Am}=$ yellow/orange color fruit; $\mathrm{VC}=$ light red color fruit; VI = dark red fruit.

\section{Analysis of morphological characters}

Nine quantitative variables were selected based on multicollinearity diagnosis for the study of genetic diversity: total fruit yield (TY, in t/ha), fruit length (FL, in $\mathrm{cm}$ ), diameter of the stalk scar (DSS, cm), total soluble solids content (SS, ${ }^{\circ}$ Brix, measured using a digital refractometer); fruit firmness [FF, mean value of the force $(\mathrm{N})$ required to penetrate the tomato fruit skin, measured by a fixed digital penetrometer]; titratable acidity (TA); vitamin C content (VC, mg ascorbic acid per $100 \mathrm{~g}$ pulp), phenolic compounds (mg gallic acid per $100 \mathrm{~g}$ pulp), and $\mathrm{pH}$ (mean hydrogenionic potential measured with a digital $\mathrm{pH}$ meter). 
The genetic diversity between lines (based on agronomic variables) was determined by a multivariate technique called cluster analysis using the Tocher's optimization method, described by Cruz et al. (2012). Initially, the generalized Mahalanobis $\left(D_{i^{\prime}}^{2}\right)$ distance, which is a dissimilarity measure between lines, was estimated. Based on this set of distances, the lines were clustered into groups. The analysis procedure adopts the criterion that the mean intragroup distance is lower than any intergroup distance. The maximum mean intra-group distance was set as the maximum $D_{i}^{2}$, value obtained in the set of shortest distances involving all lines. Additionally, the diversity between lines was assessed in scatter plots, using the scores of the first two canonical variables, as described by Cruz et al. (2012). At the same time, the relative importance of the variables to investigate the genetic diversity was estimated by the methodology proposed by Singh (1981).

\section{Molecular analysis}

To estimate the genetic dissimilarity of lines based on molecular data, 10 industrial tomato lines were sown in polystyrene trays to obtain plant material for DNA extraction. The 15-cm high seedlings were cut and ground in liquid nitrogen for DNA extraction. For this procedure, about $100 \mathrm{mg}$ ground leaf tissue was transferred to tubes containing $2.0 \mathrm{~mL}$ extraction buffer. The buffer and procedures for DNA extraction were performed as described by Sharma et al. (2008). DNA was quantified on $0.8 \%$ agarose gels $(\mathrm{w} / \mathrm{v})$ by electrophoresis at $100 \mathrm{~V}$ for $40 \mathrm{~min}$. The DNA concentration was determined by comparison with a standard DNA of known concentration.

The DNA of the lines used as parents in the diallel was amplified by PCR using 12 ISSR primers. The PCR was prepared as follows: $40 \mathrm{ng}$ genomic DNA, 1X PCR buffer, 1.5 $\mathrm{mM} \mathrm{MgCl}{ }_{2}, 200 \mu \mathrm{M}$ dATP, $200 \mu \mathrm{M}$ dTTP, $200 \mu \mathrm{M}$ dCTP, and $200 \mu \mathrm{M} \mathrm{dGTP,} 10 \mathrm{mmol}$ primer, $1 \mathrm{U}$ Taq DNA polymerase, and water to a volume of $12.5 \mu \mathrm{L}$. For amplification, the thermal cycler was programmed for an initial 5 -min cycle at $95^{\circ} \mathrm{C}$ for DNA denaturation, followed by 35 cycles at $94^{\circ} \mathrm{C}$ for $30 \mathrm{~s}$, primer annealing temperature for $45 \mathrm{~s}$ (Table 5), and $72^{\circ} \mathrm{C}$ for 2 $\mathrm{min}$. At the end of 35 cycles, a final extension step was performed at $72^{\circ} \mathrm{C}$ for $7 \mathrm{~min}$. The PCR products were resolved on 3\% agarose gels and stained with ethidium bromide.

Only primers with a good resolution pattern of the amplified products were used. The plants were genotyped for the presence (1) or absence (0) of bands and a binary matrix was constructed from these data. The percentage of polymorphism of each ISSR primer was calculated as the ratio between the total number of polymorphic fragments divided by the total number of amplified fragments. The genetic dissimilarity between plants was measured by the Jaccard coefficient and the dissimilarity dendrogram between plants was constructed using the unweighted pair group method with arithmetic mean (UPGMA). The reliability of the nodes of the dendrogram was obtained by bootstrap resampling, with 1000 iterations. To determine the cut point in the genetic divergence dendrogram, the method proposed by Mojena (1977) was used for the calculation, by the expression $\theta_{k}=\bar{\alpha}+K \hat{\sigma}_{\alpha}$ where $\theta_{k}$ is the cutoff of the dendrogram, and $\bar{\alpha}$ and $\hat{\sigma}_{\alpha}$ are the mean and standard deviations of the distances corresponding to stage $\mathrm{j}$, and $\mathrm{K}$ is a constant of 1.25, as described by Cruz et al. (2011). To test the efficiency of the clustering method, the cophenetic correlation coefficient was calculated. 


\section{Correlations}

A study of correlations (Pearson and Spearman) of the genetic distances between the ten lines ( $D_{i,}^{2}$ and Jaccard) with estimates of heterosis (based on the mean of the parents), specific combining ability, and the mean observed for the variables in TY, (in t/ha), pulp yield (PY, t/ha), and SS ( ${ }^{\circ}$ Brix). To prove the existence of a correlation between the genetic dissimilarity matrices obtained by ISSR molecular markers and agronomic variables, the Mantel $t$-test $(\mathrm{P} \leq 0.05)$ was performed. The statistical and genetic analyses were performed using the software Genes (Cruz, 2013).

\section{RESULTS AND DISCUSSION}

\section{Morphological markers}

In genetic divergence studies, the phenotypic traits used should be neither redundant (correlated) nor invariant (no variation between genotypes), so that the variables considered would represent the fundamental structure of the biological system under study. Thus, in genetic divergence studies, the criterion of choice of quantitative traits was the significance of treatment effects (lines) in analysis of variance $(\mathrm{P} \leq 0.05)$ and a low multicollinearity between the selected response variables. Multicollinearity is defined as the degree to which any variable effect can be predicted or explained by other variables as a basic assumption of the cluster analysis, and can prevent erroneous analysis results, when duly exploited (Cargnelutti Filho et al., 2009). The end value of multicollinearity observed for these nine characteristics was considered low (72.64), validating the cluster analysis performed later (Cruz et al., 2011).

The relative contribution of the agronomic variables and quality of tomato fruits to the study of genetic divergence was evaluated by the method proposed by Singh (1981) (Figure 1). The variables $\mathrm{pH}$ and TA of the fruits contributed with 61.84 and $13.12 \%$ of the genetic variability among accessions, respectively, and together accounted for approximately $75 \%$ of the total genetic variability, highlighting the important role of these variables in genetic diversity studies of tomato.

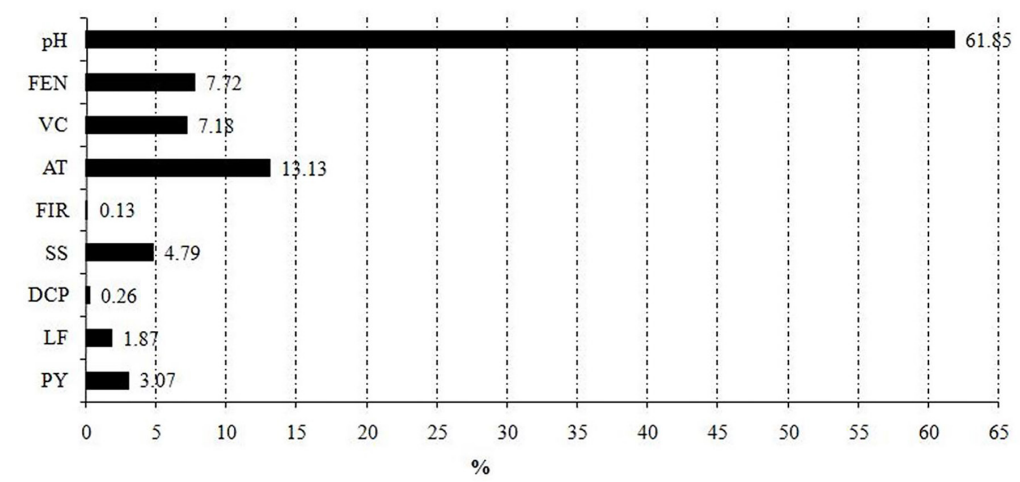

Figure 1. Relative importance of agronomic characteristics and qualities postharvest to the study of genetic divergence in industrial tomato, according to the methodology of Singh (1981). TY = total productivity of fruits; $\mathrm{LF}=$ length of fruit; $\mathrm{DSS}=$ diameter of the stalk scar; $\mathrm{SS}=$ soluble solids; $\mathrm{FF}=$ fruits firmness; $\mathrm{TA}=$ titratable acidity; $\mathrm{VC}=$ vitamin $\mathrm{C} ; \mathrm{PC}=$ phenolic compounds and $\mathrm{pH}$ of pulp. 
The importance of the variables in the study of genetic divergence is also indicated by the magnitude of the weighting coefficient from the last canonical variables; the traits with highest magnitude should be excluded in future studies (Cruz et al., 2011). Thus, considering the weights for the last two canonical variables, it is observed that the variable $\mathrm{FF}\left(\mathrm{VC}_{9}\right.$ and weighting coefficient 0.991$)$ and DSS ( $\mathrm{VC}_{8}$ and weighting coefficient 0.959$)$ should be excluded in future studies (Table 2). However, it is noteworthy that the same variables (DSS and FF) were also indicated by the Singh method (1981) as those that contributed least to the study of genetic diversity, and should be excluded from future studies of genetic diversity in tomato.

Figure 2 shows the results of cluster analysis by the Tocher's method, based on Mahalanobis generalized distances $\left(D_{i i^{\prime}}^{2}\right)$ and the graphic dispersion of the genotypes, based on the first two canonical variables (Table 2). In general, the interpretation of genetic diversity by grouping and by dispersion in coordinate systems was coincident. Thus, this agreement of results is linked to the fact that the first two canonical variables accumulated $86.13 \%$ of the total available variation between lines $(66.02 \%$ is related to the first canonical variable and the other $20.11 \%$ to the second canonical variable), thereby validating the study of genetic divergence in tomato lines by Cartesian projection, using the first two canonical variables (Table 2).

Table 2. Eingen values based on variation percentages explained by canonical variables and relative importance of nine quantitative agronomic characteristics and fruit quality evaluated in ten inbred lines of industrial tomato.

\begin{tabular}{|c|c|c|c|c|c|c|c|c|c|c|c|}
\hline \multirow[t]{2}{*}{$\mathrm{VC}_{\mathrm{i}}$} & \multicolumn{2}{|c|}{ Eingen values } & \multicolumn{9}{|c|}{ Traits relative importance } \\
\hline & $\lambda_{\mathrm{i}}$ & $\%$ acum & TY & $\mathrm{FL}$ & DSS & SS & FF & TA & $\mathrm{VC}$ & PC & $\mathrm{pH}$ \\
\hline $\mathrm{VC}_{1}$ & 460.02 & 66.02 & 0.690 & 0.177 & -0.130 & -0.278 & 0.135 & 0.264 & -0.354 & -0.161 & 1.238 \\
\hline $\mathrm{VC}_{2}$ & 140.06 & 86.13 & -0.246 & -0.733 & 0.544 & 0.327 & -0.207 & -1.014 & 0.765 & 0.852 & 0.188 \\
\hline $\mathrm{VC}_{3}$ & 42.93 & 92.29 & 0.503 & 0.455 & -0.751 & 0.968 & 0.168 & 0.706 & 0.141 & 0.889 & -0.128 \\
\hline $\mathrm{VC}_{4}$ & 23.46 & 95.66 & 0.948 & 0.790 & -0.588 & 0.716 & -0.516 & -0.387 & -0.284 & 0.0003 & 0.111 \\
\hline $\mathrm{VC}_{5}$ & 20.45 & 98.60 & 0.478 & 0.254 & 0.003 & -0.022 & -0.220 & 0.063 & 0.759 & -0.379 & 0.0347 \\
\hline $\mathrm{VC}_{6}$ & 5.30 & 99.36 & 0.095 & 0.672 & -0.086 & -0.594 & 0.125 & -0.123 & 0.127 & 0.286 & -0.093 \\
\hline $\mathrm{VC}_{7}$ & 3.60 & 99.87 & 0.734 & -0.606 & 0.364 & -0.034 & -0.356 & 0.002 & -0.084 & 0.058 & -0.027 \\
\hline $\mathrm{VC}_{8}$ & 0.80 & 99.99 & -0.199 & 0.0007 & 0.959 & 0.092 & 0.155 & 0.013 & -0.093 & -0.010 & 0.020 \\
\hline $\mathrm{VC}_{9}$ & 0.33 & 100 & -0.034 & -0.043 & -0.117 & 0.50 & 0.991 & -0.034 & 0.046 & -0.036 & 0.029 \\
\hline
\end{tabular}

$\mathrm{TY}=$ total productivity of fruits; $\mathrm{LF}=$ length of fruit; $\mathrm{DSS}=$ diameter of the stalk scar; $\mathrm{SS}=$ soluble solids; $\mathrm{FF}=$ fruits firmness; $\mathrm{TA}=$ acidity titratable; $\mathrm{VC}=$ vitamin $\mathrm{C} ; \mathrm{PC}=$ phenolic compounds; and $\mathrm{pH}$ of pulp.

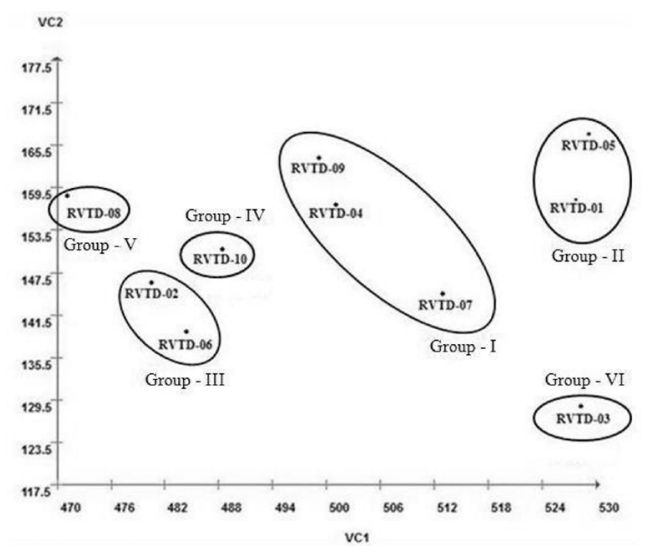

Figure 2. Graphic dispersion of inbred lines of industrial tomato in relation to the first two canonical variables and identification of groups according the Tocher optimization method. 
According to the Tocher's optimization method, plants of the same group are more homogeneous than plants of different groups, while, according to the chart diagram, plants at short distances are less dissimilar than those spaced far apart. Tocher's clustering formed six groups (Figure 2): group 1 with genotypes RVTD I-04, RVTD-07 and RVTD-09 [lines with Italian tomato (saladete), with a light red and intense color, 120-day cycle] (Table 1). Group II consists only of parents RVTD-01 and RVTD-05 (lines with Santa Cruz and Italian fruits, 122-day cycle, relatively low yield, with high levels of mesocarp thickness). RVTD-01 produced fruits with highest mean weight, but orange-colored, hampering their use in industrial tomato breeding programs (Table 1). Group III contains genotypes RVTD-02 and RVTD-06 (both lines with Santa Cruz fruits, 120day cycle, SS content above $4.0^{\circ}$ Brix and a thick mesocarp). Groups IV, V and VI consisted, respectively, of the parents RVTD-08, RVTD-10 and RVTD-03 (Table 1).

The mean for $D_{i i}^{2}$, between the lines was 1393.40 , varying from 171.83 in the parent pair RVTD-04 and RVTD-09 up to 4185.90 between the parents RVTD-04 and RVTD-08 (Table 3). Line RVTD-08 was grouped in a separate group from the other genotypes, as a result of the considerable higher genetic dissimilarity of this than of the other parents (Figure 2). Line RVTD-08 has a cycle of around 121 days, Italian fruit type, and two to three loci of intense red color, mesocarp thickness of $7.97 \mathrm{~mm}$, and a good SS content $\left(4.66^{\circ} \mathrm{Brix}\right)$.

Table 3. Generalized distance of Mahalanobis (below the diagonal) and percent genetic divergence by Jaccard coefficient obtained by molecular markers ISSR (above the diagonal) between inbred lines of industrial tomato.

\begin{tabular}{|c|c|c|c|c|c|c|c|c|c|c|}
\hline & RVTD-01 & RVTD-02 & RVTD-03 & RVTD-04 & RVTD-05 & RVTD-06 & RVTD-07 & RVTD-08 & RVTD-09 & RVTD-10 \\
\hline RVTD-01 & 0 & 46.15 & 64.29 & 58.33 & 45.46 & 54.55 & 60.00 & 76.92 & 50.00 & 66.67 \\
\hline RVTD-02 & 2457.37 & 0 & 46.67 & 60.00 & 60.00 & 66.67 & 61.54 & 66.67 & 53.33 & 66.67 \\
\hline RVTD-03 & 910.06 & 2706.68 & 0 & 66.67 & 75.00 & 73.33 & 69.23 & 81.25 & 50.00 & 73.33 \\
\hline RVTD-04 & 766.43 & 687.51 & 1649.30 & 0 & 50.00 & 58.33 & 50.00 & 93.75 & 53.85 & 69.23 \\
\hline RVTD-05 & 276.41 & 2997.30 & 1563.12 & 1135.57 & 0 & 58.33 & 63.64 & 69.23 & 64.29 & 69.23 \\
\hline RVTD-06 & 2404.16 & 307.85 & 2251.32 & 840.54 & 2913.12 & 0 & 72.73 & 85.71 & 50.00 & 22.22 \\
\hline RVTD-07 & 501.57 & 1273.88 & 564.26 & 366.71 & 927.86 & 1038.75 & 0 & 92.31 & 40.00 & 72.73 \\
\hline RVTD-08 & 3355.73 & 374.28 & 4185.90 & 1074.09 & 3527.33 & 836.41 & 2057.50 & 0 & 94.12 & 93.33 \\
\hline RVTD-09 & 928.65 & 882.51 & 2209.63 & 171.83 & 1154.97 & 929.99 & 673.38 & 1073.57 & 0 & 50.00 \\
\hline RVTD-10 & 1949.16 & 762.67 & 2361.69 & 496.02 & 2353.33 & 616.30 & 849.01 & 741.48 & 597.56 & 0 \\
\hline
\end{tabular}

No significant estimates $(\mathrm{P} \geq 0.05)$ of both Pearson and Spearman correlations were observed between $D_{i i}^{2}$, and heterosis, specific combining ability, and mean of the variables TY and PY, indicating that the $D_{i^{\prime}}^{2}$ estimates cannot be used directly to choose the parents to be combined to obtain high-yielding and heterotic hybrids (Table 4). On the other hand, for the variable SS, low, but significant $(\mathrm{P} \leq 0.05)$ Pearson and Spearman correlation coefficients were observed between the $D_{i i}^{2}$, and two parents, and the observed mean in their respective hybrids (Table 4), indicating that hybrids with the highest mean SS were the result of the combination of genetically divergent parents, making $D_{i^{\prime}}^{2}$ a good choice for the orientation of the most promising crosses, facilitating the procedure in developing industrial tomato hybrids with a high SS content of the raw material.

Several studies have investigated the use of $D_{i,}^{2}$ in the prediction of the best tomato hybrids. Maluf et al. (1983) correlated $D_{\tilde{i}^{\prime}}^{2}$ values and mean Euclidean distance with the heterosis of hybrids obtained by interbreeding six indeterminate tomato varieties and observed a strong correlation between the genetic dissimilarity between parents and the heterosis observed in hybrids. They concluded that the genetic dissimilarity between both parents estimated with quantitative morphological markers can be used effectively in predicting the best tomato hybrids. On the other hand, Mulge et al. (2012) correlated $D_{i i}^{2}$, with the heterosis 
of tomato hybrids and found no significant Pearson correlation estimates for TY and SS, discarding the use of the $D_{i i^{\prime}}^{2}$ obtained by continuous quantitative variables in the prediction of the best tomato hybrids. The genetic divergence obtained by $D_{i}^{2}$, is based on quantitative (discrete and continuous) and qualitative (multicategoric) variables obtained in experiments. Therefore, they are susceptible to environmental influences on phenotypic expression (Morales et al., 2011b), which hinders its use in some cases, and is the reason for the low correlation coefficients in most studies (Gonçalves et al., 2008).

Table 4. Pearson and Spearmann correlation coefficients between the estimates of generalized distance of Mahalanobis, and index of Jaccard dissimilarity. Average heterosis $(\mathrm{H})$, specific combining ability $\left(\hat{\mathrm{S}}_{\mathrm{ij}}\right)$, and average of variable total fruit productivity (TY), yield pulp (PY) and total content of soluble solids (SS), observed in 45 hybrid combinations obtained from complete diallel crosses.

\begin{tabular}{|c|c|c|c|c|c|c|c|c|c|}
\hline \multirow[t]{3}{*}{ Variable } & & \multicolumn{4}{|c|}{ Pearson } & \multicolumn{4}{|c|}{ Spearrmann } \\
\hline & & $D_{i i^{\prime}}^{2}$ & Jaccard & $\mathrm{H}$ & $\hat{\mathrm{S}}_{\mathrm{ij}}$ & $D_{i i^{\prime}}^{2}$ & Jaccard & $\mathrm{H}$ & $\hat{\mathrm{S}}_{\mathrm{ij}}$ \\
\hline & Jaccard & -0.10 & - & - & - & -0.04 & - & - & - \\
\hline \multirow[t]{3}{*}{ TY } & $\mathrm{H}$ & 0.16 & 0.02 & - & - & 0.2 & -0.07 & - & - \\
\hline & $\hat{\mathrm{S}}_{\mathrm{ij}}$ & 0.11 & 0.04 & $0.86^{* *}$ & - & 0.07 & -0.06 & $0.81 * *$ & - \\
\hline & Average & 0.09 & $0.30 *$ & $0.75^{* *}$ & $0.89^{* *}$ & 0.18 & $0.26^{*}$ & $0.66^{* *}$ & $0.80^{\text {*** }}$ \\
\hline \multirow[t]{3}{*}{ PY } & $\mathrm{H}$ & 0.23 & -0.05 & - & - & 0.24 & -0.12 & - & - \\
\hline & $\hat{\mathrm{S}}_{\mathrm{ij}}$ & 0.26 & -0.08 & $0.93 * *$ & - & 0.19 & -0.07 & $0.88 * *$ & - \\
\hline & Average & 0.21 & $0.27 *$ & $0.81 * *$ & $0.88^{* *}$ & 0.27 & $0.28 *$ & $0.74 * *$ & $0.81^{\text {*** }}$ \\
\hline \multirow[t]{3}{*}{ SS } & $\mathrm{H}$ & 0.14 & -0.08 & - & - & 0.08 & -0.08 & - & - \\
\hline & $\hat{\mathrm{S}}_{\mathrm{ij}}$ & 0.19 & -0.07 & $0.96^{* *}$ & - & 0.13 & -0.11 & $0.94 * *$ & - \\
\hline & Average & $0.30^{*}$ & 0.11 & $0.86^{* * *}$ & $0.92 * *$ & $0.32 *$ & 0.10 & $0.80 * *$ & $0.88^{* * *}$ \\
\hline
\end{tabular}

*Significant by $\mathrm{F}$ test $(\mathrm{P} \leq 0.05)$.

Genetic diversity is an imperative prerequisite for heterosis, but not necessarily sufficient to ensure it, since heterosis depends not only on differences in allele frequencies, but also on dominance and epistatic interactions (Oliboni et al., 2012). However, in an attempt to explain this absence of correlation, one hypothesis would be that in the case of quantitative traits such as TY and PY, cases of bi-directional dominance could occur, i.e., some loci are dominant in one direction and others in the opposite direction.

Positive and highly significant $(\mathrm{P} \leq 0.01)$ correlation coefficients were observed for both Pearson and by Spearman, between mean and heterosis, medium and specific combining ability and heterosis, and specific combining ability, indicating that the hybrids with highest phenotypic values for the variables TY, PY and SS were obtained from hybrid combinations with high heterosis and specific combining ability. Consequently, hybrids with higher heterosis were derived from hybrid combinations with higher specific combining ability. Estimates of heterosis and specific combining ability are closely interrelated genetic parameters, because both depend on genes with non-additive effects.

\section{Molecular markers}

Eight of the 12 ISSR primers had high-quality amplification products and polymorphisms (Table 5). The primers UBC-861, UBC-864, UBC-873, and UBC-878 were excluded from the analysis because of the insufficient amplification quality and/or for being monomorphic. The eight ISSR primers amplified 74 bands, of which 21 were polymorphic (Table 5). Each primer amplified in the mean 9.25 bands, of which 2.62 were polymorphic 
(Table 5). The mean polymorphism of the primers was $27.62 \%$, and the sizes of the amplified bands ranged from 240 to $1800 \mathrm{bp}$ (Table 5).

Table 5. Primer ISSR, base sequence 5'-3', temperature of annealing (TA), number of amplified bands (NTB), number of polymorphism bands (NBP), polymorphism percentage, and gap of band size (TB).

\begin{tabular}{l|c|c|c|c|c|c}
\hline Primer & Sequence 5'-3' & Ta $\left({ }^{\circ} \mathrm{C}\right)$ & NTB & NBP & P (\%) & TB (bp) \\
\hline UBC-807 & $(\mathrm{AG})_{8} \mathrm{~T}$ & 55 & 9 & 5 & 55 & $240-950$ \\
\hline UBC-808 & $(\mathrm{AG})_{8} \mathrm{C}$ & 50 & 10 & 4 & 40 & $250-1700$ \\
\hline UBC-809 & $(\mathrm{AG})_{8} \mathrm{G}$ & 55 & 9 & 1 & 11 & $280-1100$ \\
\hline UBC-810 & $(\mathrm{GA})_{8} \mathrm{~T}$ & 50 & 11 & 5 & 45 & $300-1500$ \\
\hline UBC-811 & $(\mathrm{GA})_{8} \mathrm{C}$ & 53 & 7 & 2 & 28 & $490-900$ \\
\hline UBC-815 & $(\mathrm{CT})_{8} \mathrm{G}$ & 53 & 6 & 1 & 16 & $600-1800$ \\
\hline UBC-835 & $(\mathrm{AG})_{8} \mathrm{YC}$ & 54 & 10 & 1 & 10 & $250-1200$ \\
\hline UBC-836 & $(\mathrm{AG})_{8} \mathrm{YA}$ & 53 & 12 & 2 & 16 & $280-1400$ \\
\hline Total & - & - & 74 & 21 & - & - \\
\hline Average & - & - & 9.25 & 2.62 & 27.62 & - \\
\hline
\end{tabular}

Terzopoulos and Bebeli (2008) evaluated the genetic divergence in 41 broad-based tomato accessions (landrace cultivars and wild accessions), and obtained $57.8 \%$ polymorphic bands of 102 bands, amplified with a mean of 4.9 polymorphic bands per primer. These authors concluded that ISSR markers are an excellent tool to analyze genetic diversity in tomato, and are helpful in choosing parents in breeding programs. Aguilera et al. (2011) evaluated 10 ISSR primers in 96 tomato accessions and observed similar results as in this study, with $36.80 \%$ polymorphic bands of a total of 144 amplified bands. In addition, Ray (2010) concluded that ISSR markers in tomato can generate a high degree of polymorphism; in his study, the polymorphism of 12 ISSR primers in 6 tomato varieties was $56 \%$. The reason that our results are below those reported in the literature can be the magnitude of the genetic basis of genotypes. The above studies assessed a germplasm with a broad genetic base, whereas the lines evaluated in our experiment have a high degree of homozygosity and narrow genetic basis, which is a common characteristic of the Brazilian tomato cultivars (Gonçalves et al., 2008; Melo et al., 2009).

The most polymorphic primers in this study were $807(\mathrm{AG})_{8} \mathrm{~T}, 810(\mathrm{GA})_{8} \mathrm{~T}$, and 808 $(\mathrm{AG})_{8} \mathrm{C}(\mathrm{AG})_{8} \mathrm{C}$, with 55,45 , and $40 \%$ polymorphism, respectively (Table 5). Aguilera et al. (2011) also indicated primer $810(\mathrm{GA})_{8} \mathrm{~T}$ as the most polymorphic, with $45 \%$ amplified polymorphic bands. These authors explain that the high polymorphism of primer $810(\mathrm{GA})_{8} \mathrm{~T}$ in tomato accessions was due to the specific sequence of guanine and adenine bases of this primer.

The mean genetic dissimilarity between the industrial tomato lines estimated by the Jaccard coefficient by means of ISSR markers was $63.70 \%$, ranging from $22.22 \%$ between the parents RVTD-06 x RVTD-10 to 94.12\% between RVTD-08 and RVTD-09 (Table 3).

The cophenetic correlation coefficient ( $r$ ) obtained with Jaccard's genetic distance of dissimilarity was $0.84 * *$ and the $t$-value of $10.45(\mathrm{P} \leq 0.01)$ suggested an excellent fit between the graphical representation of the distances and their original matrix (Figure 3 ). The consistency of the dendrogram branches reflects the genetic divergence among accessions assigned to a particular group in the dendrogram, indicating that the groups actually contain the most similar genotypes. This information is extremely important for breeding, since the most similar genotypes are generally not used in crosses because production of plants with high heterosis cannot be expected from parents that are genetically very closely related. As a rule, a branch is considered consistent in a cluster analysis, if the Bootstrap value exceeds $50 \%$. Therefore, in this study, the clusters related to parents RVTD-07 and RVTD-09 (40.4\%) 
and RVTD-04 with RVTD-07 (40.3\%) are considered inconsistent, while the other nodes are regarded as reliable enough for the cluster analysis, i.e., moving the loci, these groups are necessarily reproduced (Figure 3).

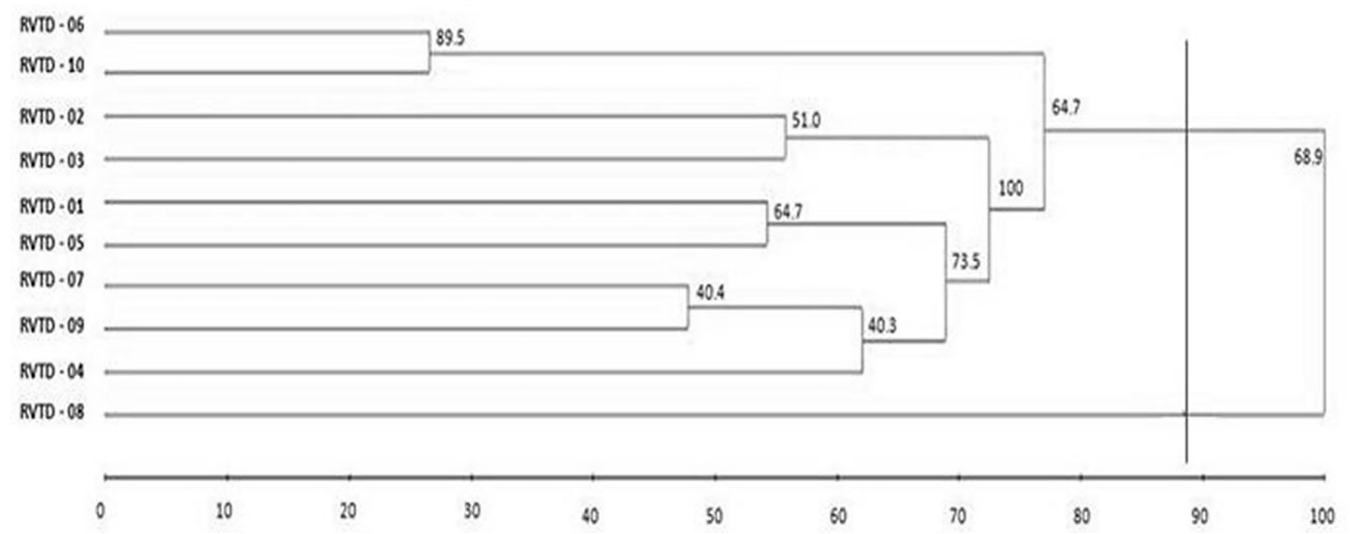

Figure 3. Dendrogram of genetic dissimilarity between ten inbred lines of industrial tomato, obtained by UPGMA method, based on ISSR molecular markers, using the Jaccard distance.

The cutoff point obtained according to Mojena (1977) was 0.74 , dividing the dendrogram into two groups (Figure 3). Line RVTD-08 was isolated in group I, and indicated as the most divergent line of this study (Figure 3), with genetic dissimilarity values ranging from $66.67 \%$ with parent RVTD-06, to $94.12 \%$ when combined with line RVTD-09 (Table $3)$. According to both agronomic traits and ISSR markers, line RVTD-08 was allocated in a separate group from the other genotypes, as a result of the considerable genetic dissimilarity of this parent from the others. It is noteworthy that line RVTD-08 has appropriate phenotypic characteristics as a parent in future programs for breeding of industrial tomato, particularly when targeting high-yielding and heterotic hybrids.

Group II consisted of the nine other lines used in this study. Some lines are noteworthy, e.g., RVTD-07 with high fruit yield of the Italian type, with clear red color and excellent thick mesocarp $(8.97 \mathrm{~mm})$, ensuring FF during transport from the field to the processing unit. Fruit ripening of RVTD-07 is concentrated, and harvesting begins 115 days after sowing. Another interesting parent is RVTD-10, which has a high total content of soluble solids $\left(4.70{ }^{\circ} \mathrm{Brix}\right)$ in the thick fruit mesocarp $(8.22 \mathrm{~mm})$ and Italian-type fruit. RVTD-01 has orange-colored fruits. This is a serious issue because the tomato market demands fruits with an extremely red color for processing, due to the higher lycopene content in these fruits. However, it is worth noting that the high mean fruit weight of this line $(80.79 \mathrm{~g} /$ fruit $)$ and its high mesocarp thickness $(8.47$ $\mathrm{mm}$ ) ensures excellent firmness during storage and transport.

\section{Morphological and molecular markers}

The greater the genetic divergence between both parents, the greater the chance that the hybrid is heterotic and high-yielding, and its descendants have wide genetic variability, enabling the selection of superior transgressive genotypes, essential for plant breeding (Gonçalves et al., 2008; Mulge et al., 2012). The Pearson and Spearman correlation coefficients of the 
present study, which was significant $(\mathrm{P} \leq 0.05)$ and positive, between the genetic dissimilarity of the tomato lines and the mean of their respective hybrids for the variables TY and PY, are in line with these previous studies, indicating that hybrids with highest TY and PY resulted from a combination of the most divergent lines by ISSR loci (Table 4). Thus, the results of this study validate ISSR molecular markers as an important tool in predicting the best hybrids of industrial tomato with regard to TY and PY, guiding the breeder to the combination of lines that can produce the most promising hybrids, with time and cost savings.

Most previous studies on ISSR markers address genetic diversity and germplasm characterization (Morales et al., 2011a; Aguilera et al., 2011), with a focus on the genetic distance between any two genotypes, suggesting the possibility of successful breeding. However, few studies focus on the genetic dissimilarity with ISSR markers to estimate relevant biometric parameters for plant breeding. Shapturenko et al. (2014) used nine ISSR primers for 23 chili accessions and achieved $28 \%$ polymorphism in 56 amplified bands. Based on genetic distances, the 10 most divergent parents were selected and intercrossed with each other and the hybrids evaluated for heterosis and mean fruit yield. These authors found a strong correlation between the ISSR marker-based genetic distance and the observed heterosis in the hybrids derived from the cross of the most divergent parents, corroborating the results obtained in the present study. Thus, the above results suggest that ISSR molecular markers can be used effectively in predicting crosses in crops in which hybrid exploitation is feasible, orienting breeders to perform only the most promising crosses.

To prove the results of the correlations (Table 4), the hybrid combination RVTD 08-x-09 RVTD can serve as an example, which had both the highest estimate of heterosis (exceeding the parental mean by $85.20 \%$ ) and the highest mean fruit yield of the experiment $(84.37 \mathrm{t} / \mathrm{ha})$. The pronounced high yield and heterosis are explained by the specific combining ability between lines RVTD-08 and RVTD-09, indicating that one line was able to correct and/or complement defects of the other at the loci involved in the control of fruit yield, in which the predominant gene action is non-additive. On the other hand, the least divergent hybrid combination by ISSR markers, derived from the parents RVTD-06 and RVTD-10 had a relatively low overall fruit yield $(47.03 \mathrm{t} / \mathrm{ha})$, below the mean yield of some lines of the experiment, low heterosis (only $7.75 \%$ above the parent mean), and negative specific combining ability $(-9.38 \mathrm{t} / \mathrm{ha})$. This indicates that the lines most often share the same alleles involved in the control of TY, preventing the lines from complementing each other perfectly.

The results of this study indicate that ISSR molecular markers are effective in identifying contrasting parents for hybrid production in tomato. Parent RVTD-08 was the most divergent in this study, indicated both by molecular and morphological markers, positively contributing to increased heterosis and specific combining ability in the crosses in which it participated as parent. The genetic dissimilarity estimated by molecular markers ISSR was useful to identify the best hybrid of the experiment with regard to total fruit yield, pulp yield, and soluble solids content.

\section{Conflicts of interest}

The authors declare no conflict of interest

\section{ACKNOWLEDGMENTS}

Research supported by Coordenação de Aperfeiçoamento de Pessoal de Nível Superior 
(CAPES), Conselho Nacional de Desenvolvimento Científico e Tecnológico (CNPq), and the Brazilian Innovation Agency FINEP. The authors also thank the NUPH and the Laboratory of Plant Genetics and Molecular Biology of UNICENTRO for the support and infrastructure provided for this project.

\section{REFERENCES}

Aguilera JG, Pessoni LA, Rodrigues GB, Elsayed AY, et al. (2011). Genetic variability by ISSR markers in tomato (Solanum lycopersicon Mill.). Rev. Bras. Cienc. Agrár. 6: 243-252.

Cargnelutti Filho A, Storck L and Ribeiro ND (2009). Agrupamento de cultivares de feijão na ausência e presença de multicolinearidade. Cienc. Rural 39: 2409-2418. http://dx.doi.org/10.1590/S0103-84782009000900005

Cruz CD (2013). GENES - a software package for analysis in experimental statistics and quantitative genetics. Acta Sci. Agron. 35: 271-276. http://dx.doi.org/10.4025/actasciagron.v35i3.21251

Cruz CD, Ferreira FM and Pessoni LA (2011). Biometria aplicada ao estudo da diversidade genética. 1 ed. Suprema, Visconde de Rio Branco.

Cruz CD, Regazzi AJ and Carneiro PCS (2012). Modelos biométricos aplicados ao melhoramento genético. UFV, Viçosa.

Gonçalves LSA, Rodrigues R, Sudré CP, Bento CS, et al. (2008). Divergência genética em tomate estimada pormarcadores RAPD em comparação com descritores multicategóricos. Hortic. Bras. 26: 364-370. http://dx.doi.org/10.1590/ $\underline{\mathrm{S} 0102-05362008000300014}$

Maluf WR, Ferreira PE and Miranda JEC (1983). Genetic divergence in tomatoes and its relationship with heterosis for yield in hybrids. Rev. Bras. Genet. 6: 453-460.

Mattedi AP, Guimarães MDA, Nick C, Silva DJH, et al. (2014). Genetic divergence of tomato subsamples. Rev. Ceres 61: 70-76. http://dx.doi.org/10.1590/S0034-737X2014000100009

Melo PCT, Melo AMT and Boiteux LS (2009). Overview and perspectives of tomato breeding for fresh market adapted to mild tropical climates of Brazil. Acta Hortic. 821: 55-62. http://dx.doi.org/10.17660/ActaHortic.2009.821.4

Mojena R (1977). Hierarchical grouping methods and stopping rules: an evaluation. Comput. J. 20: 359-363. http://dx.doi. org/10.1093/comjnl/20.4.359

Morales RGF, Resende JTV, Faria MV, Andrade MC, et al. (2011a). Genetic similarity among strawberry assessed by RAPD and ISSR markers. Sci. Agric. 68: 665-670. http://dx.doi.org/10.1590/S0103-90162011000600010

Morales RGF, Resende JTV, Faria MV, Silva PR, et al. (2011b). Divergência genética em cultivares de morangueiro, baseada em caracteres morfoagronômicos. Rev. Ceres 58: 323-329. http://dx.doi.org/10.1590/S0034-737X2011000300012

Moreira GR, Silva DJH, Picanço MC, Peternelli LA, et al. (2005). Divergência genética entre acessos de tomate iro infestados por diferentes populações da traça-do-tomateiro. Hortic. Bras. 23: 893-898. http://dx.doi.org/10.1590/ S0102-05362005000400006

Mulge R, Mahendrakar P and Prashanth SJ (2012). Prediction of heterosis based on genetic divergence in tomato. Indian J. Hortic. 69: 530-535.

Oliboni R, Faria MV, Neumann M, Battistelli GM, et al. (2012). Genetic divergence among maize hybrids and correlations with heterosis and combining ability. Acta Sci. Agron. 34: 37-44. http://dx.doi.org/10.4025/actasciagron.v34i1.11979

Oliveira VR, Scapim CA and Casalli VWD (1998). Diversidade genética e eficiência da predição do comportamento de híbridos de pimentão. Acta Sci. Agron. 20: 263-267.

Ray DP (2010). Molecular characterization of six released tomato varieties using inter simple sequence repeat markers. Indian J. Hortic 67: 328-332.

Reddy BR, Reddy MP, Begum H and Sunil N (2013). Genetic diversity studies in tomato (Solanum lycopersicum). IOSR J. Agric. Vet. Sci. 4: 53-55. http://dx.doi.org/10.9790/2380-0445355

Rocha MC, Gonçalves LSA, Do Carmo MF and Abboud ACS (2010). Uso do algoritmo de Gower na determinação da divergência genética entre acessos de tomateiro do grupocereja. Acta Sci. Agron. 32: 423-431. http://dx.doi. org/10.4025/actasciagron.v32i3.4888

Santos FFB, Ribeiro A, Siqueira WJ and Melo AMT (2011). Desempenho agronômico de híbridos $\mathrm{F}_{1}$ de tomate de mesa. Hortic. Bras. 29: 304-310. http://dx.doi.org/10.1590/S0102-05362011000300008

Shapturenko MN, Tarutina LA, Mishin L, Kilchevsky AV, et al. (2014). DNA divergence as a criterion of a sweet pepper (Capsicum annuum) selection for heterosis. Russ. J. Genet. 50: 123-130. http://dx.doi.org/10.1134/ $\underline{\mathrm{S} 1022795414020148}$

Sharma K, Mishra AK and Misra RS (2008). A simple and efficient method for extraction of genomic DNA from tropical tuber crops. Afr. J. Biotechnol. 7: 1018-1022. 
Singh D (1981). The relative importance of characters affecting genetic divergence. Indian J. Genet. Plant Breed. 41: 237-245.

Terzopoulos PJ and Bebeli PJ (2008). DNA and morphological diversity of selected Greek (Solanum lycopersicum) landraces. Sci. Hortic. (Amsterdam) 116: 354-361. http://dx.doi.org/10.1016/j.scienta.2008.02.010

Vilela NJ, Melo PCT, Boiteux LS and Clemente FMVT (2012). Perfilsocio econômico da cadeia agroindustrial no Brasil. In: Produção de tomate para processamento industrial (Clemente FMVT and Boiteux LS, eds.). Embrapa-CNPH, Brasília, 17-27. 